\title{
A (des)construção do corpo em Quarto de Despejo
}

The (de)construction of the body in the Quarto de despejo. 


\section{Resumo}

Neste artigo, objetivou-se contribuir com o rol de pesquisas sobre Carolina Maria de Jesus, figura importante na literatura brasileira contemporânea, ao tecer algumas reflexões em torno da noção de (des)construção do corpo, sob o eixo das representações sociais, na obra Quarto de despejo: diário de uma favelada (2014). Para isso, considerou-se como elemento relevante o lugar de fala de Carolina de Jesus, que recria o ambiente insalubre em que viveu e projeta na materialidade linguística as diversas vozes do constructo da favela. Desse modo, mediante estudo de natureza interpretativista, partimos do estatuto teórico corpo, na Psicanálise de Jacques Lacan, e da construção e desconstrução de Antelo (2007) e Nancy (2014), de modo a indicar como é estabelecida a corporeidade da realidade comum na narrativa.

Palavras-Chave: Desconstrução; Corpo; Lugar de fala

\section{Abstract}

This article aimed to contribute to the list of research on Carolina Maria de Jesus, an important figure in contemporary Brazilian literature, and to weave some reflections around the notion of (de) construction of the body, under the axis of social representations, in the work Quarto of eviction: diary of a favela (2014). For this, it was considered as a relevant element the place of speech of Carolina de Jesus, who recreates the unhealthy environment in which she lived and projects in the linguistic materiality the different voices of the favela construct. Thus, by means of an interpretative study, we started from the theoretical body status, in the Psychoanalysis of Jacques Lacan, and from the construction and deconstruction of Antelo (2007) and Nancy (2014), in order to indicate how the corporeality of the common reality is established in narrative.

Keywords: Deconstruction; Body; Place of speech 
O presente artigo surge de algumas altercações sobre o modo como o corpo viabiliza a construção de representações sociais, na realidade (re)elaborada e narrada em Quarto de despejo: diário de uma favelada, de Carolina Maria de Jesus. Partimos do constructo de um imaginário social complexo da favela do Canindé, dissecado por uma mulher negra, que assume o lugar de fala do espaço insalubre de onde narra, isto é, considerando o ponto de vista da própria personagem. É importante salientar que essas representações entendidas aqui são fenômenos sociais, assim como nos mostra Spink, "que contribuem para a construção de uma realidade comum", condicionados e estabelecidos também pela atuação do sujeito enquanto um ser social.

Para Jodelet, autora revisitada por Spink, as representações sociais edificam-se no campo de interação entre o individual e o coletivo - dimensões emergentes do sujeito. Isso quer dizer que esse diálogo externo-interno, que constrói uma representação de dado objeto, deve ser visto não como dois polos opostos e excludentes, mas como uma unidade integradora de interpretação da realidade cotidiana. Assim, esse ser social funciona como uma instância estruturante que, consoante ao universo da palavra, é interpelado por representações mentais e representações socioculturais no plano dos sentidos. Nas palavras da autora:

As representações sociais devem ser estudadas articulando elementos afetivos, mentais, sociais, integrando a cognição, a linguagem e a comunicação às relações que afetam as representações sociais à realidade material, social e ideativa sobre a qual intervêm ${ }^{2}$.

Nesse seguimento, interessa-nos, dentro desse amplo espectro psicossocial de Jodelet, conjecturar que é inviável pensarmos em alguma representação sem a corporificação de um ser ou de uma coisa, para sustentar sua concretude. Por conseguinte, nos angariamos no estatuto teórico corpo, nosso objeto de estudo, ao acreditarmos que se constitui em um fenômeno que melhor responde à forma de como as representações sociais são estabelecidas em Quarto de despejo: diário de uma favelada, além de buscarmos destacar sua relevância para a presente discussão e para os estudos literários. Dessa maneira, caminhamos, minimamente, rumo a uma concepção de corporeidade, especificamente a lacaniana, a qual busca responder como a realidade é estruturada e quais planos são constitutivos dela.

Em contrapartida, é essencial apontar que esse objeto é mais complexo do que aparenta ser e talvez recorramos a sua superficialidade, intuindo atingir fins

1 SPINK, M. J. P. “O conceito de representação social na abordagem psicossocial”. Cadernos de Saúde Pública, 1993, p. 300.

2 Denise Jodelet, 1989, apud, ibidem, p. 304. 
metodológicos, para esclarecimento da representação em Carolina de Jesus. A própria discussão em torno do corpo não resulta em uma conceituação ingênua e imediata, porém a definição preferível para este estudo advém de Jacques Lacan, o vendo como um lugar em que ocupa o Outro. Conforme tese de doutorado de Nogueira ${ }^{3}$, Lacan, ao longo das décadas da formação epistemológica da sua teoria, busca conceber o corpo sobre três ordens de existência interligadas em um nó ${ }^{4}$, são elas: o real, o simbólico e o imaginário. Além disso, frisa-se que essa corporeidade, acertada como frágil, quando vista sobre o prisma da estrutura orgânica do homem, mostra-se em unidade funcional a contar da natureza imagética e da natureza linguística, presidida por algum ser social que atue como responsável por construir uma interpretação.

Esse enceto é crucial para compreendermos, preliminarmente, os estatutos corpo e sujeito no universo da representação. Destarte, é basilar apontar que a obra literária em pauta é uma narrativa autobiográfica de Carolina, que enuncia como narradora autodiegética seus dias de fome e de luta na sobrevivência diária e, em distintos níveis de análise, é possível percebermos processos de construção e desconstrução ${ }^{5}$, no que tange à representação pelo corpo. O ser social, que emana de um en, necessita agir sobre a linguagem para que represente, sobretudo, como um processo de construção/ organização, o qual já pressupõe instantaneamente, em uma dualidade, uma (des) construção/(des)organização de algo já existente. Esse fenômeno ocorre tanto nos contextos de produção do livro quanto na história, contida no próprio material linguístico.

Doravante, seguiremos para a contextualização de Quarto de despejo, antes de chegarmos ao seu nível de conteúdo, ambos vistos sob a óptica da representação. Pode-se afirmar que essa narrativa, redigida em meados de 1950, representa um alçamento da Literatura Feminina Negra no Brasil, constitutiva da Literatura Marginal - expressão cunhada por Antonio Candido -, na qual as mulheres negras buscam (re)construir a realidade em que vivem, como Carolina de Jesus em seu diário, para obterem "modalidades de representação próprias". Isso se deve, pois, ao cânone nacional fortemente marcado por sujeitos sócio-históricos enquadrados na ideologia

3 NOGUEIRA, Francisco Ronald Capoulade. O Estatuto do Corpo na Psicanálise de Lacan: da construção do imaginário à formalização do objeto a, 2016.

4 O nó borromeano, incorporado na Psicanálise de Jacques Lacan, é uma unidade constituída por três anéis presos entre si, a qual será dissolvida, caso um desses anéis seja removido.

5 Angariamo-nos, aqui nestes escritos, nos postulados de Nancy (2014) e Antelo (2007). Optamos também pelo uso do estatuto teórico desconstrução, correspondendo a decompor, fragmentar e não apenas eliminar ou extinguir.

6 ZINANI, Cecil Jeanine Albert. "Produção literária feminina: um caso de literatura marginal". Antares, 2014. 
dominante: homens brancos de famílias abastadas. Como denota Guimarães "No seleto cânone literário de grandes escritores, homens fomentaram a representação do sujeito feminino como subalterno"7; dessa forma, o lugar em que esse sujeito ocupava era secundarizado.

Além dessa intersecção social, recobrindo as noções de gênero e estratificação social, é necessário mencionar o fator linguístico presente na obra "Quarto de Despejo". Nela, somos apresentados a indícios singulares de uma Literatura que rompe com os escritos privilegiados da época por fazer uso de marcações não convencionais da materialidade linguística, mas que refrata uma desconstrução acentuada dessa Literatura Marginal. Obviamente, não se pode escoar o preconceito arraigado a tal variedade da língua, uma vez que Carolina Maria também sofreu preconceitos, por acreditarem que ela não havia escrito o livro e tratava-se somente de uma manifestação política na favela, como aponta o jornalista Audálio Dantas, no prefácio do livro.

Segundo Gnerre, "a linguagem constitui o arame farpado mais poderoso para bloquear o acesso ao poder", 8 ou melhor, por meio da estrutura composicional de um enunciado, os estratos sociais mais baixos poderão ser prejudicados por serem impedidos de participarem de temas relevantes para a sociedade. A título de exemplo tem-se, nos grandes veículos de informação, todo um refinamento linguístico, reordenamento morfossintático, rebuscamento, adeptos da norma, objetivando selecionar seu recebedor.

Longe de chegarmos a mais digressões e a uma descrição exaustiva sobre a escrevente, uma vez que não se pode evadir as condições sócio-históricas desse sujeito, Carolina Maria de Jesus nasceu na cidade de Sacramento - Minas Gerais, em 1914, e após algumas décadas de miséria no campo, decide deslocar-se sozinha até a grande São Paulo. Depois de perambular por vários pontos da cidade, é abruptamente apresentada à favela do Canindé, a primeira grande favela do estado de São Paulo, que na época, antes de ser desocupada na década de 1960, encontrava-se às margens do rio Tietê. Ela começa a residir em um barracão de zinco enquanto necessita todos os dias vender papelão, ferro, plástico, dentre outros materiais, que eram convertidos em dinheiro. Dinheiro este que era usado na compra de pães, açúcar e sabão, principalmente.

A autora mineira foi escolarizada até o segundo ano do ensino fundamental, entretanto apropriou-se do interesse pela literatura, no seu sentido mais genérico, viabilizado pelas aulas (já na fase adulta) com a professora Lanita Sabina, a qual não chega a ser citada explicitamente na história. A catadora de lixo foi "descoberta" pelo jornalista Audálio Dantas que, quando buscava fazer uma reportagem naquele

7 GUIMARAES, Jaciara Borges. "Uma Literatura que Transforma: Quarto de Despejo: Diário de uma Favelada de Carolina Maria de Jesus". Revista Porto das Letras, 2018, p. 102.

8 GNERRE, Maurízio. Linguagem, Escrita e Poder, 1994, p. 22. 
ambiente onde ela morava, ficou sabendo de uma mulher negra escrevente de um livro, que contava o dia a dia dos moradores da favela, de dentro da favela, através favela. Desse modo, a partir de mudanças mínimas na estrutura de seus escritos, ajudou-a a publicar o livro, que foi traduzido para mais de quinze idiomas, mas não se configurou como suficiente para retirá-la das condições de pobreza.

Além disso, apontamos, de antemão, que o supramencionado constitui um outro modo de desconstrução de como a pobreza urbana era tida na época, ou seja, não eram considerados os pontos de vista dos protagonistas envolvidos, e sim suposições levantadas de pessoas que assumiam um "lugar privilegiado", dentro da macroestrutura social, membros de uma realidade outra, perpassados por outros processos de identificações, que não os dos interagentes dos próprios espaços em que se buscavam discorrer. Destarte, nas palavras da personagem: "Devo incluir-me, porque tambem" sou favelada. Sou rebotalho. Estou no quarto de despejo, e o que está no quarto de despejo ou queima-se ou joga-se no lixo." 10

Estruturalmente, o livro é dividido em dias que compreendem os anos 1955, 1958, 1959 e o primeiro dia de 1960. Quase que estamos diante de algum círculo vicioso de desavenças, de desventuras e de fome que acometem Carolina. Embora tivesse apreço pelas crianças, tinha aversão a uma parcela considerável de homens e mulheres circunvizinhos, que assumiam determinados posicionamentos favoráveis à criminalidade, à violência, ao uso de álcool, à prostituição etc. Para ela, as condições oferecidas pelo meio eram determinantes na construção das identidades proteiformes ${ }^{11}$ dos favelados, quer dizer, o meio acabava tornando-se um fim em si mesmo, no que compete ao assujeitamento coletivo:

20 de maio de 1958 - ... As vezes mudam algumas famílias para a favela, com crianças. No inicio são iducadas, amaveis. Dias depois usam o calão, são soezes e repugnantes. São diamantes que transformam em chumbo. Transformam-se em objetos que estavam na sala de visita e foram para o quarto de despejo ${ }^{12}$

9 Os prováveis desvios na norma, como a falta de acentuação gráfica e ortografia, são extraídos da própria materialidade linguística de Quarto de despejo. O uso da forma prestigiada representa, ainda, nas palavras de Djamila Ribeiro (2017) e outros tantos teóricos da Sociolinguística e Estudos Culturais, um modo de dominação da supremacia do grupo dominante.

10 JESUS, Carolina Maria de. Quarto de despejo: diário de uma favelada, 2014, p. 37.

11 Essa expressão foi empregada no capítulo "O conceito de identidade em Linguística: é chegada a hora para uma reconsideração radical?, escrito por Rajagopalan, contido em Signorini (Lingua(gem) $e$

identidade, 1998).

12 Ibidem, p. 38. 
Constata-se, de imediato, que esse assujeitamento permite traçar uma corporeidade, na construção da realidade da favela. Consoante as noções de Lacan ${ }^{13}$ já mencionadas, o corpo é configurado por três planos ou dimensões na formação de um nó borromeano, em oposição à teoria de um corpo que fala por si mesmo. A realidade, neste viés, só poderia ser alcançada pelo: real, simbólico e imaginário; como uma construção que ao mesmo tempo contrasta-se com outras realidades. Não significando, é claro, que recorremos apenas à subjetividade de Carolina Maria de Jesus, todavia há um "compartilhamento" social que permite a algum indivíduo sugerir uma realidade coletiva (ao menos em perspectiva), conforme o terceiro eixo do nó, que demonstra ser a conversão do real pelo simbólico, para definir o eu e o Outro e as suas implicações. Nesse sentido, o corpo enquanto suposta unidade torna-se uma exterioridade ao mesmo tempo que é sorvido pelo $e$.

Para Collins, autora revisitada por Djamila Ribeiro no capítulo O que é lugar de fala, os pontos de partida ou os pontos de vista, os quais incidimos sobre os objetos do mundo (fragmentos materiais do real, convertidos pelos simbólicos e assimilados pelos interpretantes), são "condições sociais que permitem ou não que esses grupos acessem lugares de cidadania"14. Isto tudo para dizer que, embora não haja descrição minuciosa dos outros favelados, quase um apagamento das identidades na generalização de tramas terciárias, cabe à Carolina representá-los sob certo ângulo.

A título de exemplificação, em Quarto de despejo, somos apresentados a inúmeras personagens ramificadas, diversificas, com suas especificidades, ao mesmo tempo em que formam um todo opaco. É o caso de: Arnaldo (comerciante), Manoel, Nair Mathias, Silvia e esposo, D. Florela, D. Anália, D. Aparecida, D. Rosa, D. Cecilia, Maria dos Anjos, Antonio Lira, Maria José ou Zefa, Florenciana, Sr. Germano, Sr. Ireno, Ismael, Binidito, Miguel, D. Mariana, Nair Barros, D. Francisca, D. Euvira, D. Teresinha, D. Ida, D. Alice, Sr. Alfredo, Julião, D. Julita, Tiburcio, Vítor, Dona Amélia, Alexandre, Arnaldo, D, Isaltina, D. Leila; e os três filhos da personagem que enuncia: Vera Eunice, José Carlos e João José ${ }^{15}$.

Em contrapartida, cabe a nós, ainda, transitarmos para o conceito de struo apresentado por Jean-Luc Nancy ${ }^{16}$, significando "amontoar" ou “juntar", para correlacionarmos à suposta totalidade heterogênea da favela do Canindé. É justamente

13 COPPUS, A. N. S. "O lugar do corpo no nó borromeano: inibição, sintoma e angústia”. Revista Tempo Psicanalítico, 2013. p. 18.

14 RIBEIRO, Djamila. O que é: lugar de fala?, 2017, p. 38.

15 O número de personagens de $O$ quarto de despejo: diário de uma favelada não se restringe apenas aos personagens mencionados. A lista estende-se para muitos outros que, para se evitar o enfado, citamos apenas alguns.

16 NANCY, Jean-Luc. Arquivida: do sensciente e do sentido, 2014. 
esse amontoado não coordenado que acaba construindo a comunidade de modo assistemático e desconstruindo os muros da interculturalidade relacional ${ }^{17}$ falseada que busca, a todo momento no sistema social capitalista, subjugar e silenciar as minorias ${ }^{18}$. O real, nas palavras do autor, "não se dissolve, absolutamente, em irrealidade, mas ele apresenta a realidade de sua insuposição" ${ }^{19}$, lacaniando este excerto o real caracterizase por fugir do simbólico, mas a suposta realidade assimilada pelos significantes de quaisquer ordens busca materializá-lo para compreender sua improvável natureza.

A representação em Carolina do que vem a ser a favela do Canindé incide sobre o corpo, isto é, como uma unidade complexa e funcional a qual é ocupada pelo Outro. Como mencionado, o nó borromeano é composto de três planos de representação para a projeção de uma realidade. No imaginário, esse estatuto assume a dimensão de imagem; no simbólico, significante; e no real, gozo. Deteremo-nos, entretanto, preponderantemente nos dois primeiros, como delimitação da corporeidade presente em Quarto de Despejo, de modo a discorrermos a partir da obra as oscilações, longe de serem polarizadas, mas complementares, do corpo identitário da referida comunidade de São Paulo.

No excerto "Dia 22 de maio de 1958 - Duro é o pão que nós comemos. Dura é a cama que dormimos. Dura é a vida do favelado" ${ }^{20}$, percebe-se que o eu que enuncia, que se configura como o Outro, no plano simbólico, enuncia com a marcação do "nós", ante a propriedade de similitude da personagem autodiegética e o apagamento dos moradores da favela, que são, ao mesmo tempo, projetados na "centralidade" do lugar em que a favelada ocupa. A imagem projetada ao enunciatário permite apreender efeitos de sentidos específicos sobre as condições sociais do lugar deletério, que concomitantemente é refletida nas páginas do livro, isto é, o corpo enquanto significante, ganha dimensões de transmitir e ser transmitido na e pela linguagem a realidade outra presente na narrativa. A noção de (re)duplicação da realidade vivida em realidade mostrada ${ }^{21}$, que não esgota em si mesma, é análoga, em partes, ao Estádio do Espelho lacaniano:

[...] ela [a criança] experimenta ludicamente a relação dos movimentos assumidos pela imagem com seu ambiente refletido, e a desse complexo

17 Cf. Wash (2015).

18 Minorias não no sentido demográfico, mas, político.

19 NANCY, Jean-Luc. Arquivida: do sensciente e do sentido, 2014. p 40.

20 JESUS, Carolina Maria de. Quarto de despejo: diário de uma favelada, 2014, p. 41.

21 Consideramos aqui a realidade vivida como conjunto de planos de representação do nó, vivenciados pelos interagentes físicos "reais". A realidade mostrada, por sua vez, refere-se ao universo dos interagentes vividos pelas personagens do livro, corporificadas por Carolina Maria de Jesus. 
virtual com a realidade que ele reduplica, isto é, com seu próprio corpo e com as pessoas ou mesmo objetos que estejam em suas imediações ${ }^{22}$.

Nesse sentido, o ser individualizante, ou melhor, "a instância psíquica que emana da percepção" ${ }^{23}$ é exteriorizada e vista pelos olhos do tu, e cria uma imagem de si mesma e dos outros ao seu redor, para que passe a ser representada e para que represente. Em diversas passagens, constata-se a favela corporificada na constituição de Carolina Maria de Jesus, como na seguinte, cuja marcação também parte da primeira pessoa do plural: "Dia 19 de maio de 1958 - As aves devem ser mais feliz que nós. (...) O mundo das aves deve ser melhor do que dos favelados, que deitam e não dormem porque deitam-se sem comer" ${ }^{24}$. Apesar de reconhecer-se que o $e$, assim como propõe Benveniste $^{25}$, apresenta unicidade e é irredutível a uma pluralização, o nós emerge necessariamente de um enunciador na escrita, que no corpo imagético suscita vozes outras ao plano do dito.

No que compete ao corpo-texto, um estreitamento entre os aspectos do nó, recorremos a Guimarães ${ }^{26}$, que desenvolveu uma análise da narrativa $\grave{A}$ procura do vento num jardim d'agosto, de $\mathrm{Al}$ Berto, e que associa essa expressão à própria enunciação: “' $\mathrm{O}$ corpo-texto' relaciona o modo como corpo e escrita se articulam com o próprio fazer literário. Por um lado, o texto está subordinado ao corpo, e, por outro, não há qualquer distanciamento entre eles" ${ }^{27}$. Quer dizer, em relação ao Quarto de Despejo, não é possível cogitarmos na macroestrutura corporificada favela e suas nuances sem atribuirmos sua sustentação no nó borromeano da narradora e seu processo de (des)construção , que viabiliza o conhecimento do imaginário individual-coletivo das personagens da narrativa, buscando refratar, sob o eixo interpretativo, a própria realidade da comunidade.

Mediante a realidade da favela do Canindé ou o imaginário construído a partir da perspectiva de Carolina Maria de Jesus, não devemos obliterar o fato de que a (des) construção de realidades outras, ou seja, de nós borromeanos outros, faz-se presente, uma vez que a representação estabelecida não tem poder totalizante de abranger todas as coisas, a não ser em perspectiva. Esse referido imaginário, sobretudo, apresenta talvez

22 LACAN, J. O estádio do espelho como formador da função do eu, 1998, p. 97.

23 BARROSO, Adriane de Freitas. "Sobre a concepção de sujeito em Freud e Lacan”. Barbaroi, 2012, p. 152.

24 JESUS, Carolina de. Quarto de despejo: diário de uma favelada, 2014, p. 35.

25 BENVENISTE. Émile. Problemas de Linguística Geral I, 1995.

26 GUIMARÃES, Gustavo Cerqueira. Espaço, corpo e escrita em Al Berto: À procura do vento num jardim d'e agosto, 2005.

27 Ibidem, p. 76. 
uma das personagens de peso do enredo: a fome (em interface com a própria favela). Enunciados do tipo: "Eu não tinha um tostão para comprar pão"28 reproduzem-se constantemente por meiose ao longo de quase todos os dias do diário da favelada. Toda a problemática consiste na desigualdade acentuada entre os membros daquela comunidade que destinam boa parte da renda adquirida em "gêneros alimentícios", como é indiciado:

\footnotetext{
21 de maio de 1958 - Passei uma noite horrível. Sonhei que eu residia numa casa residivel, tinha banheiro, cozinha, copa e até quarto de criada. Eu ia festejar o aniversario de minha filha Vera Eunice. Eu ia comprarlhe umas panelinhas que há muito ela vive pedindo. Porque eu estava em condições de comprar. Sentei na mesa para comer. A toalha era alva ao lirio. Eu comia bife, pão com manteiga, batata frita e salada. Quando fui pegar outro bife despertei. Que realidade amarga! Eu não residia na cidade. Estava na favela. Na lama, as margens do Tietê. E com 9 cruzeiros apenas. Não tenho açucar porque ontem eu saí e os meninos comeram o pouco que eu tinha ${ }^{29}$.
}

Nesse viés, sob o pano de fundo da dimensão real, o sonho transforma-se em fuga da realidade. $\mathrm{O}$ sonho embora tenha um teor de benesse, nas atuais circunstâncias o ocorrido seria improvável, pois, apesar de representar uma suposta ascensão da personagem, pela descrição da moradia sonhada, o substancial reside na "mesa farta", na real necessidade da narradora naquele momento. A fome, adjetivada como amarela e cruel, torna-se a angústia dos menos favorecidos, angústia essa que se encontra quando o plano real (no caso, a própria necessidade biológica dos seres vivos heterotróficos) transpõe o plano imaginário (em que reside a instância do ser altero), no nó borromeano.

Além do sonho, outro meio recorrente de esquivar-se das amarras da personagem principal personificada pelas condições sociais dos interagentes da favela, Carolina escrevia. Escrevia como contramedida às consequências da fome. Novamente, constatamos o processo de destruição do que vem a ser imposto a ela, ao mesmo tempo em que é construída uma "válvula de escape", de modo a garantir a sobrevivência do corpo. Uma fuga possibilitada pelo plano do significante, da linguagem, da palavra. De acordo com Antelo, “[...] o destruidor vê saídas por toda parte e, onde outros só encontram muros ou montanhas, ele, mesmo assim, vê uma saída" ${ }^{30}$. A escrita para a narradora instrui, dignifica o ser humano, dá visibilidade:

28 JESUS, Carolina Maria de. Quarto de despejo: diário de uma favelada, 2014, p. 11.

29 Ibidem, p. 39.

30 ANTELO, Raúl. Tempos de Babel: destruição e anacronismo, 2007, p. 1. 
12 de junho de 1958 - Enquanto escrevo vou pensando que resido num castelo cor de ouro que reluz na luz do sol. Que as janelas são de prata e as luzes de brilhantes. Que minha vista circula no jardim e eu contemplo as flores de todas as qualidades. (...) É preciso criar este ambiente de fantasia, para esquecer que estou na favela ${ }^{31}$.

Nesse sentido, inferimos, a partir dos escritos de Nancy, que o processo de destruição [ou desconstrução] e construção ocorrem concomitantemente, posto que um pressupõe o outro. No arquétipo da identidade dos favelados, embora consideremse as distintas identidades, pela própria configuração do modo de narrar, percebe-se o amálgama de pessoas representadas pela narradora nas tramas terciárias, restrito aos nomes transeuntes e às breves passagens das personagens, que não deixam de constituir o corpo uno do livro: a comunidade da favela do Canindé da década de 1950.

Segundo Guimarães, “[...] a enunciação se dá pelo uso abundante da primeira pessoa, através de um "eu" que se torna, além de uma simples individualidade, um agenciador coletivo de enunciação" 32 . Embora componha um exemplo que parta de um contexto outro de produção, não se mostra distanciamento com as reflexões tidas nessa escritura. Assim, em Quarto de Despejo, percebe-se, na linguagem, a metáfora da ponte instaurada pela narradora-personagem entre si e a comunidade em que vive, conforme uma releitura do pensamento de Volóchinov ${ }^{33}$.

Como foi possível mostrar, nas proposições do livro de Carolina M. de Jesus, a recorrência do eu enunciado em nós fez-se presente, para abraçar a noção de unidade representacional, no plano simbólico, entre o exterior e o interior (complementares), sem nos perdermos nesse reducionismo. Pensando na (des)construção do corpo na obra analisada, podemos vê-lo enquanto um corpo em frangalhos, erigido a partir de um amontoados de aspectos costurados uns aos outros (noção de corporeidade, preconceito e lugar de fala), no plano de representações sociais da narrativa. Esse amontoado, viabilizado pela própria complexidade em Quarto de despejo, remete ao já mencionado conceito de struo, de Jean-Luc Nancy, que inclusive foi responsável pelo direcionamento no desenvolvimento deste estudo.

No tocante ao lugar de fala que ocupa, a autora, que emerge como ser social, recorre às vozes do coletivo para representá-los no plano simbólico da linguagem, e o apagamento citado não se refere à destruição do $t u$, mas à desconstrução no sentido de reconfigurá-lo na matriz da própria personagem: o Outro que vive na favelada, que

31 JESUS, Carolina Maria de. Quarto de despejo: diário de uma favelada, 2014, p. 58.

32 GUIMARÃES, Gustavo Cerqueira. Espaço, corpo e escrita em Al Berto: À procura do vento num jardim d'e agosto, 2005, 82.

33 VOLÓCHINOV, Valentin. Marxismo e Filosofia da Linguagem, 2018. 
é a favelada e, ao mesmo tempo, é uma exterioridade da mesma. Favelada disposta a romper com as barreiras sociais impostas, seja na sua realidade mostrada a nós, enunciatários, seja na realidade vivida e compartilhada com os moradores do Canindé.

\section{Referências Bibliográficas}

ANTELO, Raúl. Tempos de Babel: destruição e anacronismo. São Paulo: Lumne editor, 2007.

BARROSO, Adriane de Freitas. Sobre a concepção de sujeito em Freud e Lacan. Barbaroi, Santa Cruz do Sul, n. 36, 2012. Disponível em: http://pepsic.bvsalud.org/pdf/barbaroi/ n36/n36a09.pdf. Acesso em: 08 dez. 2019. p. 149-159.

BENVENISTE. Émile. Problemas de Linguística Geral I. 4. ed. Campinas: Pontes, 1995.

COPPUS, Alinne Nogueira Silva. O lugar do corpo no nó borromeano: inibição, sintoma e angústia. Revista Tempo Psicanalitico, Rio de Janeiro, 2013. Disponível em: http://pepsic. bvsalud.org/scielo.php?script=sci_arttext\&pid=S0101-48382013000100002\#: :text=Ao\%20 introduzir $\% 20 \mathrm{a} \% 20$ inibi $\% \mathrm{C} 3 \% \mathrm{~A} 7 \% \mathrm{C} 3 \% \mathrm{~A} 3 \mathrm{o} \% 2 \mathrm{C} \% 20 \mathrm{o}$,na $\% 20 \mathrm{din} \% \mathrm{C} 3 \% \mathrm{~A} 2 \mathrm{mica} \% 20$ defensiva $\% 20 \mathrm{do} \% 20$ sujeito. Acesso em: 6 dez. 2020. p. 15-27.

CUKIERT, Michele; PRISZKULNIK, Léia. Considerações sobre o eu e o corpo em Lacan. Revista de Psicologia, 2012. Disponível em: http://www.scielo.br/pdf/epsic/v7n1/10961.pdf. Acesso em: 1 dez. 2019. p. 143-149.

GALVÃO, Andreia Marcia Castro. Carolina Maria de Jesus: sua escrita, sua vida. Fênix (UFU. Online), v. 14, 2017. p. 01-17. Disponível em: https://www.revistafenix.pro.br/PDF40/ artigo_1_secao_livre_Andreia_Marcia_Castro_Galvao_fenix_jul_dez_2017.pdf. Acesso: 14 janeiro 2020.

GNERRE, Maurízio. Linguagem, Escrita e Poder. 3 ed. São Paulo: Martins Fontes, 1994.

GUIMARÃES, Gustavo Cerqueira. "Espaço, corpo e escrita em Al Berto: À procura do vento num jardim de agosto". 129f. Dissertação (Mestrado). Universidade Federal de Minas Gerais, Minas Gerais, 2005. Disponível em: https://repositorio.ufmg.br/bitstream/1843/ALDR6K3HF4/1/espa_o_corpo_e_escrita_em_al_berto.pdf. Acesso em: 13 dez. 2019.

GUIMARAES, Jaciara Borges. Uma Literatura que Transforma: Quarto de Despejo: Diário de uma Favelada de Carolina Maria de Jesus. Revista Porto das Letras, Tocantins, vol. 4, n. 2, 2018. p. 101-109. Disponível em: https://sistemas.uft.edu.br/periodicos/index.php/ portodasletras/article/download/5752/13971. Acesso em: 19 nov. 2019.

JESUS, Carolina Maria de. Quarto de despejo: diário de uma favelada. São Paulo: Ática, 2014.

LACAN, Jacques. A terceira. Cadernos Lacan, v. 2. Porto Alegre: Publicação não comercial da APPOA, 2002.

LACAN, Jacques. O estádio do espelho como formador da função do eu. Rio de Janeiro: Jorge Zahar, 1998.

LACAN, Jaques. O Seminário Livro 2: o eu na teoria de Freud e na técnica da Psicanálise. Rio de Janeiro: Jorge Zahar, 1985. 
MIITSUUCHI, Jéssica Tomiko Araújo. Contextos, reflexões e análises: Carolina Maria de Jesus e o Quarto de Despejo. Revista Vernáculo, Universidade Federal do Paraná, n. 41, 2018. p. 256-282. Disponível em: https://revistas.ufpr.br/vernaculo/article/view/50466. Acesso em: 6 dez. 2019.

NANCY, Jean-Luc. Arquivida: do sensciente e do sentido. São Paulo: Iluminuras, 2014. p. 2951.

NOGUEIRA, Francisco Ronald Capoulade. O Estatuto do Corpo na Psicanálise de Lacan: da construção do imaginário à formalização do objeto a. 193f. Tese (Doutorado). Programa de Pós-Graduação em Psicologia da Universidade Federal de São Carlos e École Doctorale Recherches en Psychanalyse et Psychopathologie de l'Université Paris-Diderot, 2016.

Disponível em: https://repositorio.ufscar.br/handle/ufscar/8860. Acesso em: 7 jun. 2020.

RIBEIRO, Djamila. O que é: lugar de fala? Belo Horizonte: Letramento, 2017.

SIGNORINI, Inês. Lingua(gem) e identidade. Campinas, SP: Mercado das Letras, 1998.

SPINK, Mary Jane Paris. O conceito de representação social na abordagem psicossocial. Cadernos de Saúde Pública, 1993. p. 300-308. Disponível em: https://www.scielo.br/pdf/csp/ v9n3/17.pdf Acesso em: 6 jun. 2020.

STERNICK, Mara Viana de Castro. A imagem do corpo em Lacan. Reverso, Belo Horizonte, v. 32, n. 59, jun. 2010. p. 31-37. Disponível em: http://pepsic.bvsalud.org/pdf/reverso/ v32n59/v32n59a04.pdf. Acesso em: 07 dez. 2019.

VOLÓCHINOV, Valentin. Marxismo e filosofia da linguagem. São Paulo: Editora 34, 2018.

WALSH, Catherine. Interculturalidad crítica y educacion intercultural (2009). In: VIAÑA, J.; TAPIA, L.; WALSH, Catherine. Construyendo Interculturalidad Crítica (2010). Disponível em: http://www.flacsoandes.edu.ec/interculturalidade/wpcontente/uploads/2012/01/ Interculturalidad-Cr\%C3\%ADtica-y-Educaión-Intercultural1.pfd. Acesso em: 15 set. 2015.

ZINANI, Cecil Jeanine Albert. Produção literária feminina: um caso de literatura marginal. ANTARES, v. 6, n. 12, jul./dez. 2014. p. 183-195. Disponível em <www.ucs.br/etc/ revistas/index.php/antares/article/viewFile/3059/1814>. Acesso em: 7 fev. 2020.

Submissão: $21 / 05 / 2020$

Aceite: $29 / 07 / 2020$

https://doi.org/10.5007/2176-8552.2019.e73668 